\title{
Multi beam observations of cosmic radio noise using a VHF radar with beam forming by a Butler matrix
}

\author{
T. Renkwitz, W. Singer, R. Latteck, and M. Rapp \\ Leibniz Institute of Atmospheric Physics at the Rostock University, Schloss-Str. 6, 18225 Kühlungsborn, Germany
}

\begin{abstract}
The Leibniz-Institute of Atmospheric Physics (IAP) in Kühlungsborn started to install a new MST radar on the North-Norwegian island Andøya $\left(69.30^{\circ} \mathrm{N}, 16.04^{\circ} \mathrm{E}\right)$ in 2009. The new Middle Atmosphere Alomar Radar System (MAARSY) replaces the previous ALWIN radar which has been successfully operated for more than 10 years. The MAARSY radar provides increased temporal and spatial resolution combined with a flexible sequential point-to-point steering of the radar beam. To increase the spatiotemporal resolution of the observations a 16-port Butler matrix has been built and implemented to the radar. In conjunction with 64 Yagi antennas of the former ALWIN antenna array the Butler matrix simultaneously provides 16 individual beams. The beam forming capability of the Butler matrix arrangement has been verified observing the galactic cosmic radio noise of the supernova remnant Cassiopeia A. Furthermore, this multi beam configuration has been used in passive experiments to estimate the cosmic noise absorption at $53.5 \mathrm{MHz}$ during events of enhanced solar and geomagnetic activity as indicators for enhanced ionization at altitudes below $90 \mathrm{~km}$. These observations are well correlated with simultaneous observations of corresponding beams of the co-located imaging riometer AIRIS $\left(69.14^{\circ} \mathrm{N}, 16.02^{\circ} \mathrm{E}\right)$ at $38.2 \mathrm{MHz}$. In addition, enhanced cosmic noise absorption goes along with enhanced electron densities at altitudes below about $90 \mathrm{~km}$ as observed with the co-located Saura MF radar using differential absorption and differential phase measurements.
\end{abstract}

\section{Introduction}

The Leibniz-Institute of Atmospheric Physics (IAP) in Kühlungsborn has been studying the dynamics and structure of the lower and middle atmosphere at polar latitudes for more than 15 years. For this purpose IAP operated for

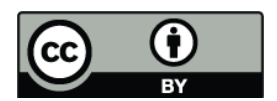

Correspondence to: T. Renkwitz (renkwitz@iap-kborn.de) about 10 years the ALWIN MST radar system at $53.5 \mathrm{MHz}$ (Latteck et al., 1999) on the North-Norwegian island Andøya $\left(69.30^{\circ} \mathrm{N}, 16.04^{\circ} \mathrm{E}\right)$. A phased antenna array consisting of 144 Yagi antennas was used to form 6 degree wide beams on transmission and reception. Especially, the characteristics of Polar Mesospheric Summer Echoes (PMSE) have been studied with high time resolution. In 2009 IAP started to build the more flexible and powerful successor system MAARSY (Middle Atmosphere Alomar Radar System, Latteck et al., 2010). The new radar consists of a phased array of 433 individual 3-element Yagi antennas arranged in an equilateral grid structure and the same amount of transceiver modules. Since the installation of this versatile radar system observations in the troposphere and mesosphere with, until now, sequential beam steering have been carried out.

In the current manuscript, we present an approach of simultaneous multi beam capability as extension to the MAARSY system. For this purpose a 16-port Butler matrix has been built, which allows to form simultaneously 16 individual beams in combination with 64 Yagi antennas of the former ALWIN antenna array.

In the following chapters we describe the architecture of the beam forming matrix and the system used for the observations presented in this study. Afterwards we describe two methods to verify the beam forming capability of the Butler matrix arrangement by the observation of cosmic radio noise originating from a radio source. Furthermore we will compare events of local ionospheric absorption monitored with this multi beam architecture and the co-located imaging riometer AIRIS. Finally we present a summary of the results and conclusions.

\section{System description}

The ALWIN64 antenna array consists of 64 4-element Yagi antennas composed of 16 individual antenna groups with a regular antenna spacing of $3.97 \mathrm{~m}$. These 16 antenna groups were either directly connected to the receiver to e.g. generate a narrow beam or were switched to a 16-port Butler matrix.

Published by Copernicus Publications on behalf of the URSI Landesausschuss in der Bundesrepublik Deutschland e.V. 


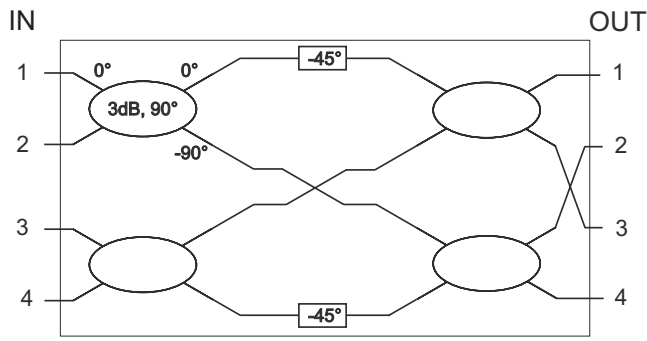

Fig. 1. Layout of a 4-port Butler matrix, where the ellipses depict $90^{\circ}$ half-power combiners and the rectangles marked with $-45^{\circ}$ denote phase shifters.

It is generally known that a radar beam can be steered off the broadside by implying a progressive time- or phase-offset to the individual array antennas. The idea of a Butler-matrix is to generate several simultaneous beams by the superposition of the corresponding phases needed to excite every beam individually. A Butler matrix built in hardware is generally composed of half-power $90^{\circ}$ combiners and phase shifters, first described by Butler and Lowe (1961). Each half-power $90^{\circ}$ combiner merges signals from two sources to one output adding a $90^{\circ}$ phase shift, while both inputs are isolated to each other. The same combiner may also be used to split one input into two outputs including the $90^{\circ}$ phase shift for one port. Additionally, these combiners provide a fourth port which is normally used to dump the energy that got reflected at the output due to impedance mismatch. In the case of adequate impedance match this port is isolated from the others. Due to this property of a half-power $90^{\circ}$ combiner the individual in- and outputs of a Butler matrix are isolated to each other. To arrange an appropriate phase distribution to the output ports, in half of the paths through the Butler matrix, phase shifters are included. In such a structure the total number of available beams is determined by the amount of independent receivers and antenna feeds. A 4-port Butler matrix simultaneously generates four individual in- and outputs and is depicted in Fig. 1. In combination of four adjacent groups of the ALWIN64 antenna array with a 4-port Butler matrix four individual beams are formed simultaneously at zenith angles of approximately $\pm 5^{\circ}$ and $\pm 14^{\circ}$. For the current 16 channel radar receiver of the MAARSY system a 16-port Butler matrix was built by the concatenation of eight 4-port Butler matrices. Using this 16-port Butler matrix with the ALWIN64 array 16 individual beams with linear polarization and a beam width of approximately $9^{\circ}$ are generated. For the height of PMSE-layers, this beam width results in a target area of roughly $14 \mathrm{~km}$ diameter for each single beam. This configuration of beam forming matrix and the ALWIN64 antenna array have been described in Renkwitz et al. (2010). The layout of the 16-channel Butler matrix and the idealized beam pattern (side lobes removed) are shown in Fig. 2. After the integration of the Butler-matrix into the ALWIN-system receiver, measurements of the losses in mag-

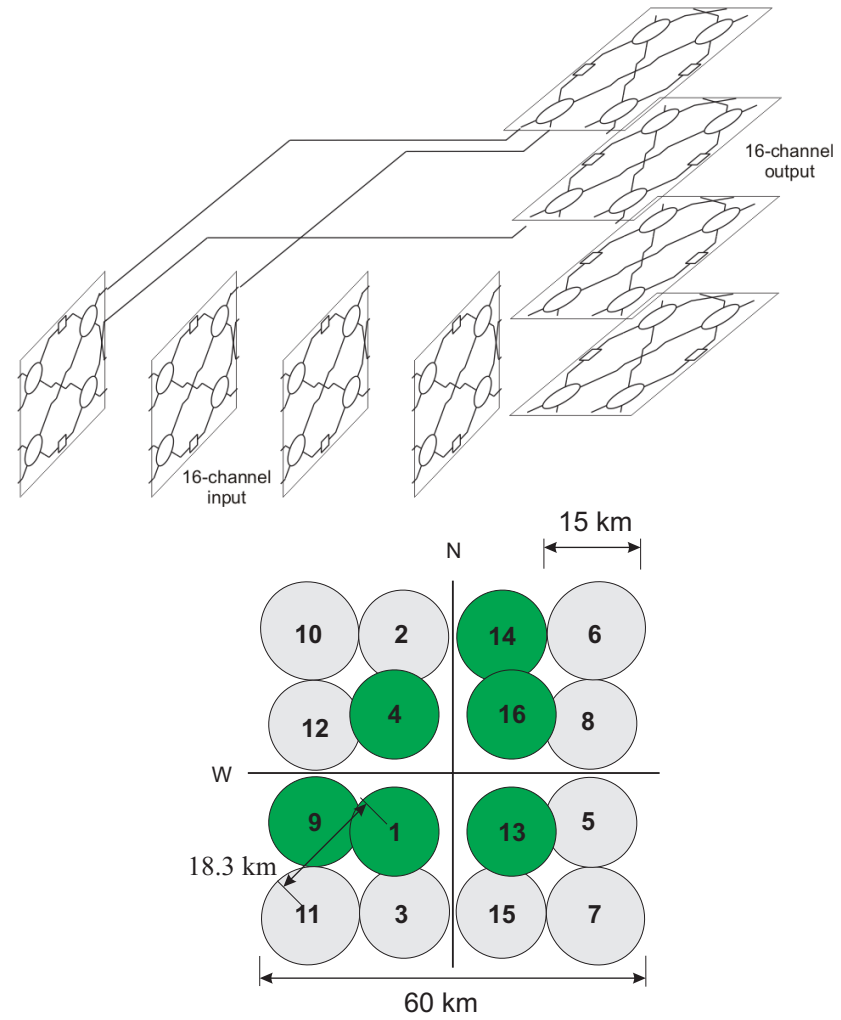

Fig. 2. Top: Layout of the 16-channel Butler matrix used in this study composed of a concatenation of eight 4-port Butler matrices. Bottom: The idealized multi beam radiation pattern (side lobes removed) in a projection to $85 \mathrm{~km}$ height generated with the combination of the 16-port Butler matrix and ALWIN64 antenna array. The numbers denoted in the ellipses refer to the corresponding port of the Butler matrix, where the beams marked in green are used within this study.

nitude and phases of the Butler-matrix and the antenna array have been carried out to ensure the theoretical performance of the setup. The magnitude and phase measurements of the total 16-port Butler matrix underlined the appropriateness of the selected components used to built the matrix. Furthermore, the results of this examination have been used to simulate the radiation pattern of the system with NEC (Numerical Electromagnetics Code) including mutual coupling of the individual antennas and the influence of lossy ground. The computed radiation pattern for all 16 beams are presented in Fig. 3. The deviation to the initially assumed radiation pattern was found to be negligible. Within these 16 individual beams, four beams with an off-zenith direction of $6.8^{\circ}$, eight beams with an off-zenith direction of $15^{\circ}$ and four beams with an off-zenith direction of $20^{\circ}$ are generated. Generally, with the increase of off-zenith beam pointing angle the radiation pattern deteriorates as the attenuation of side lobes is decreased. The reason for this degradation in the radiation pattern is the arrangement of four antennas to a group with a common feed point. Furthermore this antenna array 

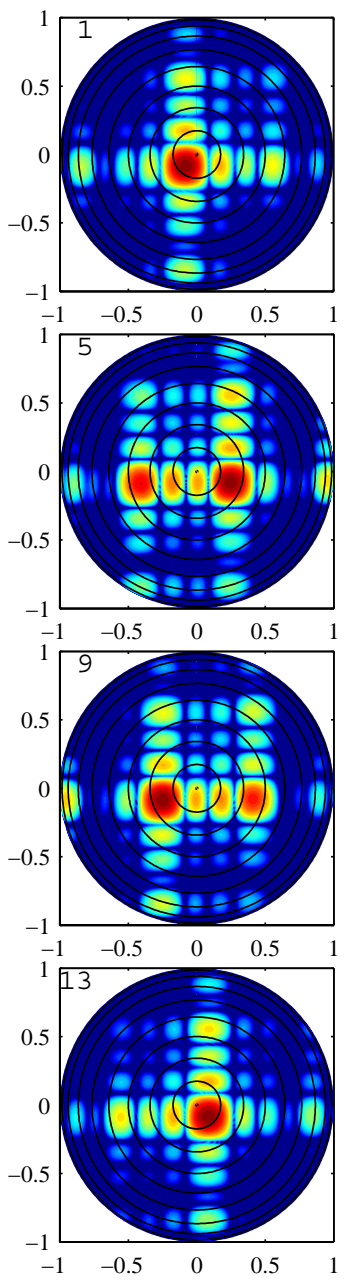
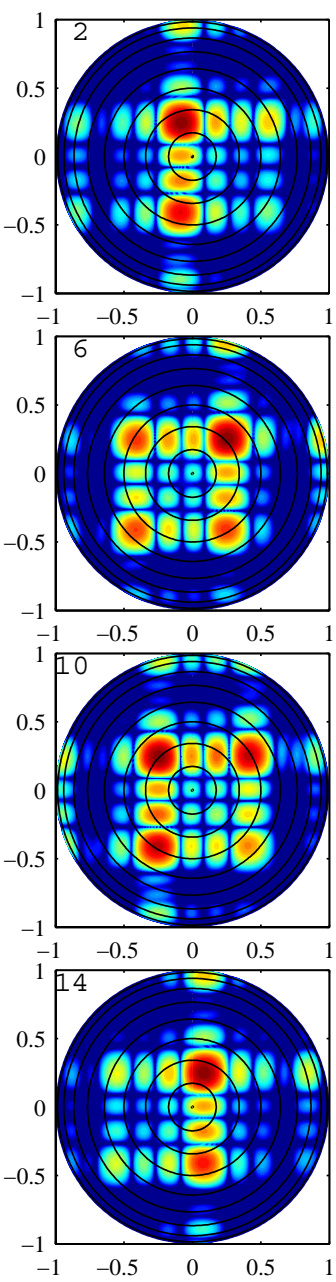
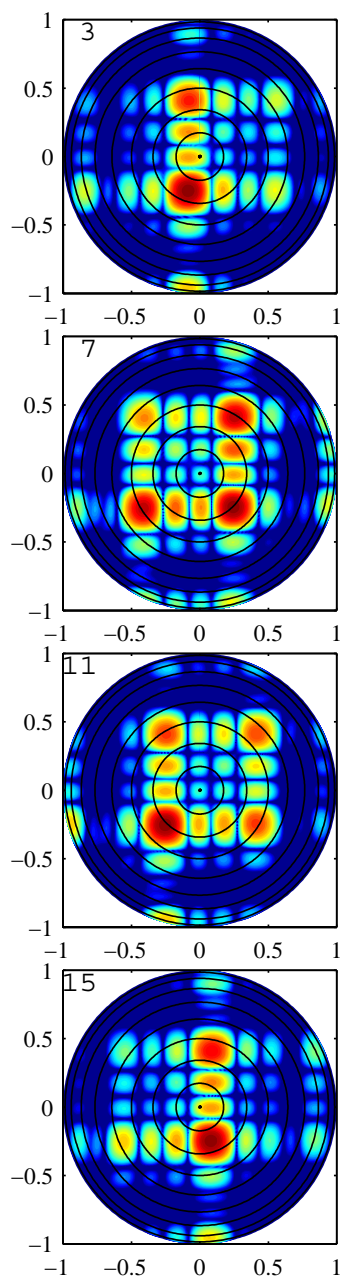
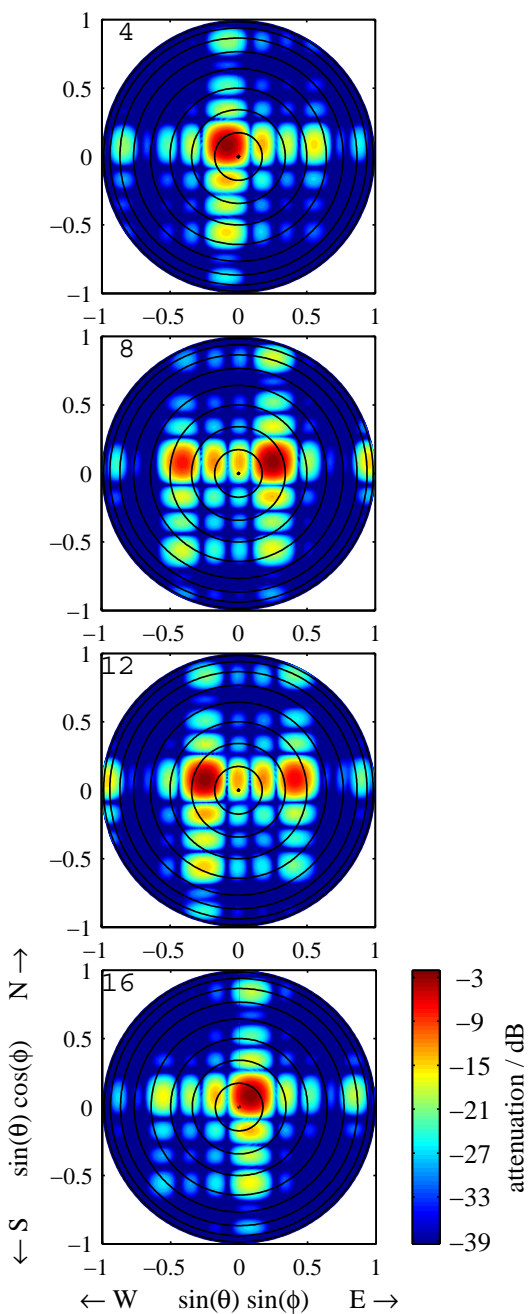

Fig. 3. Computed radiation pattern of the multi beam configuration using a 16-port Butler matrix and the 64 Yagi antenna array ALWIN64. Depicted are the radiation pattern of 16 simultaneously generated beams relative to the maximum gain with an overlay of equidistant rings of each $10^{\circ}$ zenith angle. For this simulation the Numerical Electromagnetics Code (NEC) with the Norton-Sommerfeld approximation was used implicating the mutual coupling of antennas and the influence of imperfect ground. The corresponding beam number is depicted in the upper left corner of each individual pattern.

architecture, where the individual antennas are placed on a regular squared grid structure, induces the generation of grating lobes, which can be seen for 15 and $20^{\circ}$ off-zenith beam pointing. Consequentially we generally focused on using the innermost beams with an off-zenith angle of $6.8^{\circ}$. However, for monitoring localized effects in the atmosphere also the remaining beams can be used with adequate cautiousness. To prohibit potential errors due to the misalignment of the individual receiver gain settings, we adjusted the observed noise power to a common reference. Therefore all channels of the ALWIN receiver have been terminated with a $50 \Omega$ load while the power of all channels have been obtained with the same receiver and experiment settings employed afterwards, especially for the gain and bandwidth. Thus, for each individual receiver we derived an averaged noise power and we defined the receiver 1 as common reference. Subsequently the incident noise of the following observations have been adjusted in relation to this common reference receiver noise, which allows to compare the incident noise power in subsequent experiments.

\section{Observations and discussion}

Since the installation of the 16-port Butler matrix in November 2009 the ALWIN64 antenna array has been used in passive mode to sample cosmic noise. Six out of 16 beams have been selected to verify the functionality of the Butler matrix e.g. by monitoring the supernova remnant Cassiopeia A and were therefore connected to the ALWIN 6-channel receiver. 

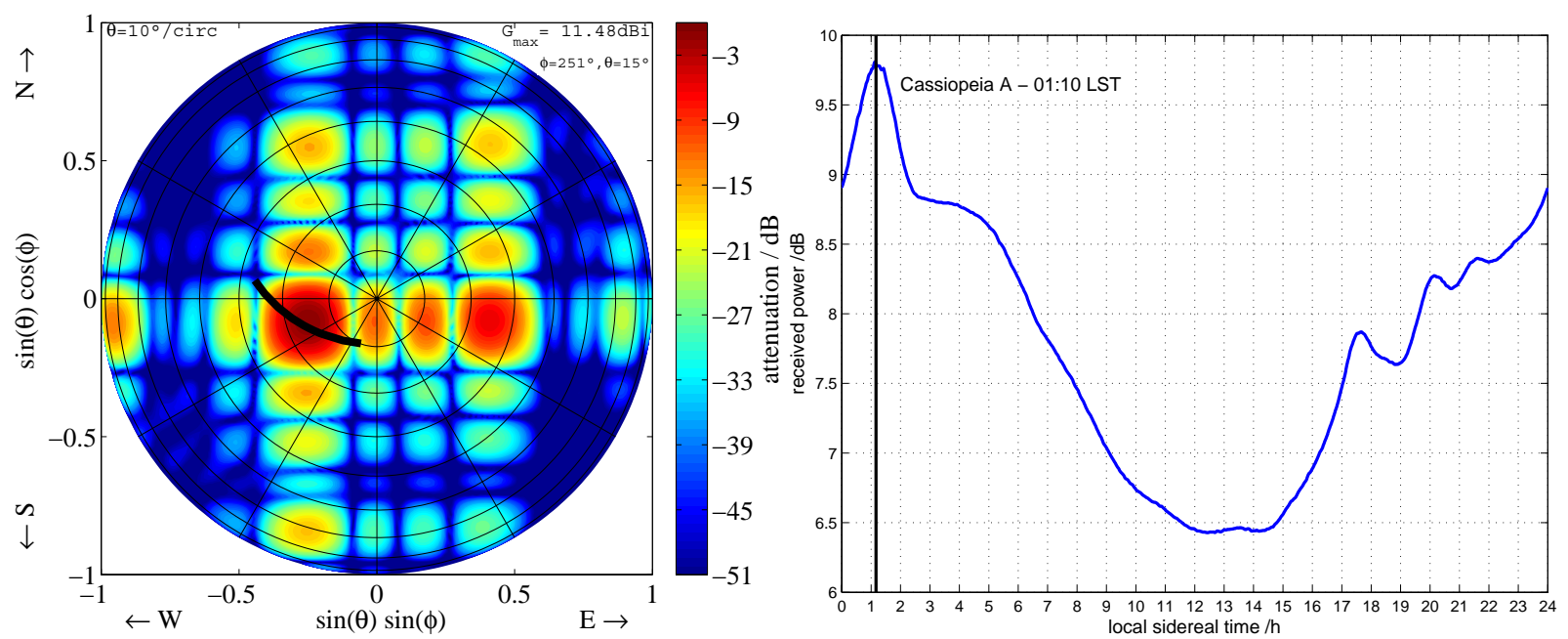

Fig. 4. Left: radiation pattern of the ALWIN-Butler beam 9 overlayed with the trajectory projection of Cassiopeia A. Right: Quiet Day Curve for the ALWIN-Butler beam 9 monitoring the passage of Cassiopeia A. The passage of Cassiopeia A through the antenna beam appears on the local sidereal time 01:10 with an average of received noise power of $9.8 \mathrm{~dB}$ over receiver noise.

The corresponding beams are marked in Fig. 2 and a summary of the selected beams is presented in Table 1. For this study interference-free data from 15 days of observations in November 2009 have been used to estimate a Quiet Day Curve (QDC) for each individual beam. With the estimated QDC it was possible to derive the exact time of the apparent crossing of Cassiopeia A through the corresponding antenna beam. For the observation of Cassiopeia A the beam direction of the ALWIN-Butler beam 9 was found to give the best overlap with the path of the radio source. The radiation pattern of this beam including a projection of the trajectory of Cassiopeia A and the received noise power detected at ALWIN-Butler beam 9, relative to the local sidereal time, are illustrated in Fig. 4. The maximum power for the crossing of Cassiopeia A was determined to be $9.8 \mathrm{~dB}$ above receiver noise at the sidereal time $01 \mathrm{~h} 10 \mathrm{~m} 36 \mathrm{~s}$. At this specific local sidereal time, the position of Cassiopeia A in the sky has been calculated as follows: azimuth $240.9^{\circ}$ and zenith $15.5^{\circ}$ relative to the position of the radar. However, the direction of maximum gain of the corresponding ALWINButler beam has been calculated with NEC to be generated at the azimuth angle $251.2^{\circ}$ and zenith angle of $15.2^{\circ}$ with a half-power beam width of $9.3^{\circ}$. The overlay of the simulated radiation pattern and the trajectory of Cassiopeia A revealed the best fit for the direction of azimuth $246.5^{\circ}$ and zenith $16.6^{\circ}$. This leads to the conclusion of a likely offset in the pointing direction of about $6^{\circ}$ for ALWIN-Butler beam 9 . A possible reason for this beam pointing error might be an impedance mismatch between the antennas and the Butler matrix. In this case the earlier described isolation between the in- and output ports might be deteriorated resulting in a modification of the generated beam steering phases. However, during the installation of the Butler matrix no conspic-
Table 1. Identifiers and directions of beams of the ALWIN-Butler and AIRIS riometer used for the comparison of ionospheric absorption. Azimuth and zenith angles are denoted by $\phi$ and $\theta$ respectively. A projection of these beams to $85 \mathrm{~km}$ height is shown in Fig. 5.

\begin{tabular}{cll}
\hline location & $\begin{array}{c}\text { ALWIN-Butler } \\
69.30^{\circ} \mathrm{N}, 16.04^{\circ} \mathrm{E}\end{array}$ & $\begin{array}{c}\text { AIRIS riometer } \\
69.15^{\circ} \mathrm{N}, 16.03^{\circ} \mathrm{E}\end{array}$ \\
\hline beam & $1: \phi=225^{\circ}, \theta=6.8^{\circ}$ & $25: \phi=0^{\circ}, \theta=0^{\circ}$ \\
no. & $9: \phi=251^{\circ}, \theta=15.2^{\circ}$ & $17: \phi=315^{\circ}, \theta=20.4^{\circ}$ \\
$\&$ & $13: \phi=135^{\circ}, \theta=6.8^{\circ}$ & $18: \phi=0^{\circ}, \theta=14.2^{\circ}$ \\
directions & $16: \phi=45^{\circ}, \theta=6.8^{\circ}$ & $19: \phi=45^{\circ}, \theta=20.4^{\circ}$ \\
\hline
\end{tabular}

uous impedances have been found. The return loss due to impedance mismatch of the individual antenna groups have been measured to be about $-20 \mathrm{~dB}$ in worst case, which describes a still well matched antenna.

Another valuable experiment is the comparison of derived cosmic noise absorption to data of the co-located riometer (relative ionospheric opacity meter) AIRIS $\left(69.14^{\circ} \mathrm{N}\right.$, $16.02^{\circ} \mathrm{E}$, Andoya Rocket Range, and Lancaster University, SPEARS Group). The AIRIS riometer is almost identical to the IRIS riometer built earlier in Kilpisjärvi, Finland, which have been described and used by e.g. del Pozo et al. (2002) and Kero et al. (2007). A riometer measures the incident noise power received from galactic radio sources and its damping caused by its propagation through the D-region of the ionosphere. It is well known from the magneto-ionic theory that this damping occurs as a consequence of collisions between free electrons and neutrals and hence maximises at altitudes between about $80-90 \mathrm{~km}$. The current state of this absorption layer may vary in height and intensity depending 


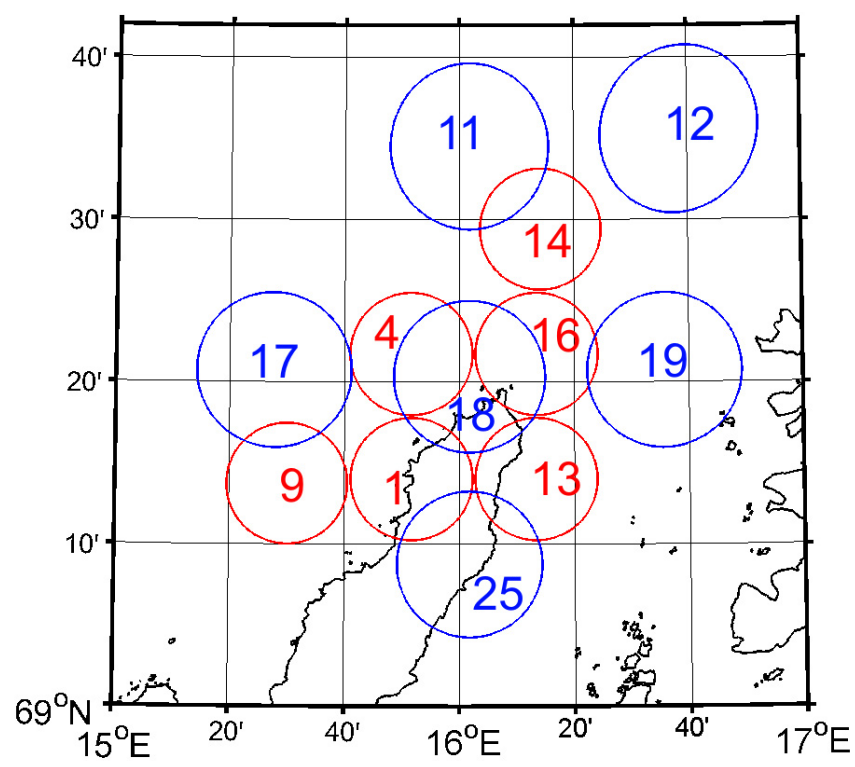

Fig. 5. Projection of the co-located ALWIN-Butler beams (red) and AIRIS beams (blue): The corresponding ellipses depict the target area for the beams at $85 \mathrm{~km}$ according to the assumed half-power beam width.

on solar and geomagnetic activity. Additionally, the precipitation of highly energetic particles may lead to localized enhanced ionization and electron densities of significant order. The imaging riometer AIRIS provides absorption data for 49 individual spatially spread beams of circular polarization with a minimum beam width of roughly $11^{\circ}$ to $14^{\circ}$. As some beam directions of AIRIS and ALWIN64 using the Butler matrix are co-located, a comparison of absorption data derived with both systems appears to be valuable to verify the theoretically simulated beam pattern. To compare absorption events with both AIRIS riometer and the multi beam configuration of ALWIN64 the system has been subsequently used to estimate the cosmic noise absorption at $53.5 \mathrm{MHz}$ during events of enhanced solar and geomagnetic activity as an indicator for enhanced ionization at altitudes below $90 \mathrm{~km}$.

The dataset of the AIRIS riometer used in this study for the subsequent comparison consists of already estimated ionospheric absorption with a coverage of 7 days (18 November 12:00 UT to 25 November 12:00 UT). Within this dataset the observations from 24 to 25 November 2009 represent the most significant signatures of ionospheric absorption. Furthermore at the same time we have seen no interferences in the ALWIN-Butler data which qualifies this specific time slot for the following analysis. In a first step corresponding beams of ALWIN-Butler and AIRIS have been selected which should show highly correlated observations. A projection of the chosen beams of ALWIN-Butler and AIRIS for a height of $85 \mathrm{~km}$ is depicted in Fig. 5. In this study we focus on four beam combinations (summarized in Table 1), which are co-located for an assumed observation height of $85 \mathrm{~km}$.

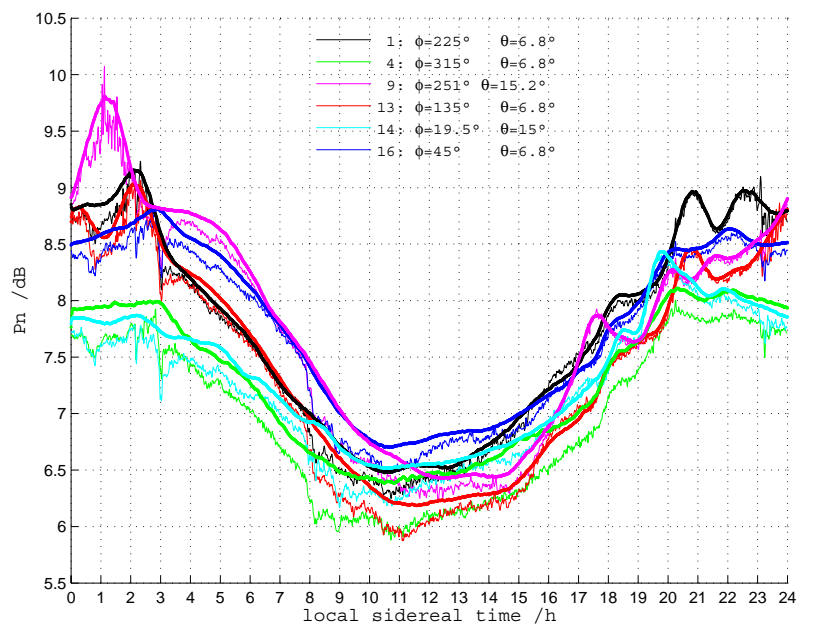

Fig. 6. Quiet Day Curve from interference-free data of 15 days (bold) and the received noise power for 6 ALWIN-Butler beams obtained for the time period of 24 November, 12:00 UT to 25 November, 12:00 UT.

The AIRIS system is located about $20 \mathrm{~km}$ south and therefore generally greater zenith beam pointing angles are necessary to overlap with beams of the ALWIN system. As to be seen below, these beams show overlapping regions with well correlated signals. The dataset of ALWIN-Butler and AIRIS has been averaged to $30 \mathrm{~s}$ samples and interpolated to the sidereal time of the beforehand estimated QDC for the ALWIN data. The time series of cosmic noise absorption for the chosen combinations of ALWIN-Butler and AIRIS beams are depicted over local sidereal time in Fig. 7, converted from the examined time period of 24 to 25 November, 12:00-12:00 UT. Generally, enhanced cosmic noise absorption goes along with enhanced electron densities at altitudes below about $90 \mathrm{~km}$. To verify the observations of AIRIS and ALWIN-Butler and the estimated absorption we have analyzed data obtained by the MF radar Saura (Singer et al., 2008, 2010), co-located to the AIRIS riometer. The median electron density profiles derived by the MF radar using differential absorption and differential phase measurements for the two time slots of 00:08-00:38 UT and 02:5903:29 UT are depicted in Fig. 8. At the time of low absorption at 00:08-00:38 UT consistently low electron densities have been observed, while for the time of significantly higher absorption also increased electron densities for the entire height coverage have been found. However, these profiles are derived for heights lower than $80 \mathrm{~km}$, we nevertheless assume a reliable detection of atmospheric absorption derived by AIRIS and the ALWIN-Butler system at the time period used in this study. The time series in general show a good agreement of the selected beam combinations of ALWINButler and AIRIS. However, at times around the local noon (LST: 14:30-17:30) the estimated absorption of AIRIS and ALWIN-Butler differ significantly. During that time on 

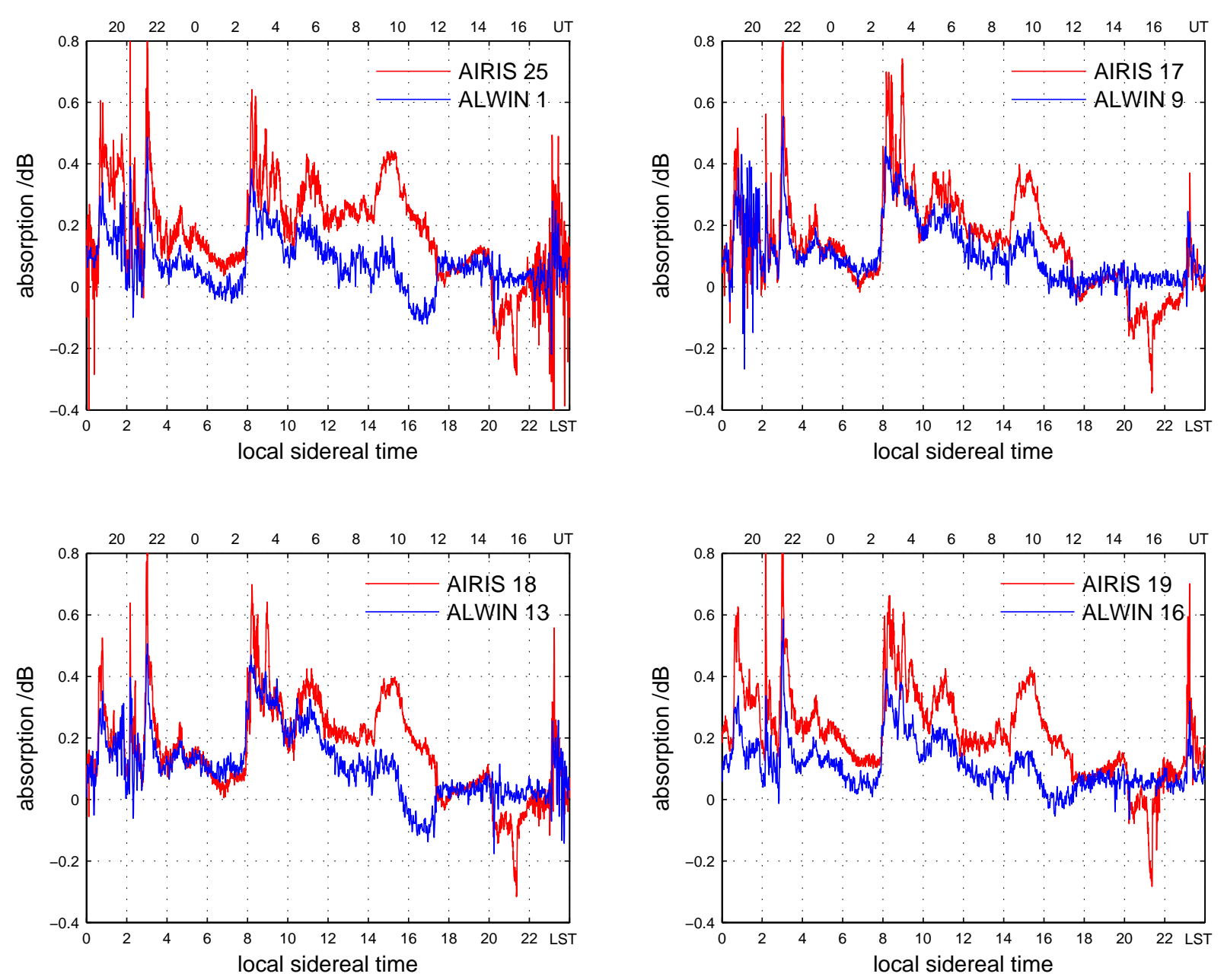

Fig. 7. Time series of absorption observed with ALWIN-Butler and AIRIS riometer for co-located beams.

25 November, the noise power detected with ALWIN-Butler has been enhanced, contrary to the observations of AIRIS. Additionally, for the complete dataset of seven days of the AIRIS riometer we found a daily increase of estimated negative absorption at times between LST 20:00-22:00. This regular diurnal repetition suggests to be a local interference at the AIRIS site. Hence, those questionable times have been discarded for subsequent analysis. The remaining data of $19 \mathrm{~h}$ observation time have been used to derive correlograms (Fig. 9), the estimation of regression and correlation coefficients, which are presented in corresponding scatter plots of the absorptions of both systems. In general we see a very good agreement for all beam combinations with high correlation coefficients between 0.89 and 0.97 . Interestingly, we found specific signatures of absorption events with differing intensity and exact time in the individual beams (e.g. at local sidereal time around 02:00 and 04:00) implying rather localized sources of these events. The sun instead would lead to a homogenous ionization, which should be seen in all beams in equal strength and therefore can be excluded as a source of the observed absorption events. Additionally, the influence of the sun to the observations have to be rather minimal as the observations have been performed in polar winter time. The systems AIRIS and ALWIN-Butler operate at significant different frequencies and the observed cosmic noise absorption data should follow a specific relation. Similar observations at different VHF frequencies have been performed by Campistron et al. (2001) that confirm the following reasoning. The cosmic noise power penetrating into the ionosphere is attenuated in dependence on frequency on the travel to the receiver. The ratio of the radio wave absorption of the ALWIN-Butler system and AIRIS system can be approximated by Eq. (1) following the magneto-ionic theory for a lossless medium.

$\frac{L_{\text {ALWIN }}}{L_{\text {AIRIS }}}=\left(\frac{f_{\text {AIRIS }}}{f_{\text {ALWIN }}}\right)^{2}$

In this equation $L_{\text {ALWIN }}, L_{\text {AIRIS }}$ and $f_{\text {ALWIN }}, f_{\text {AIRIS denote }}$ the derived absorption values and the operating frequencies of the systems. We note that the cosmic noise signals incident on the ionosphere are also frequency dependent in themselves and obey a similar relation as given in Eq. (1) but with 


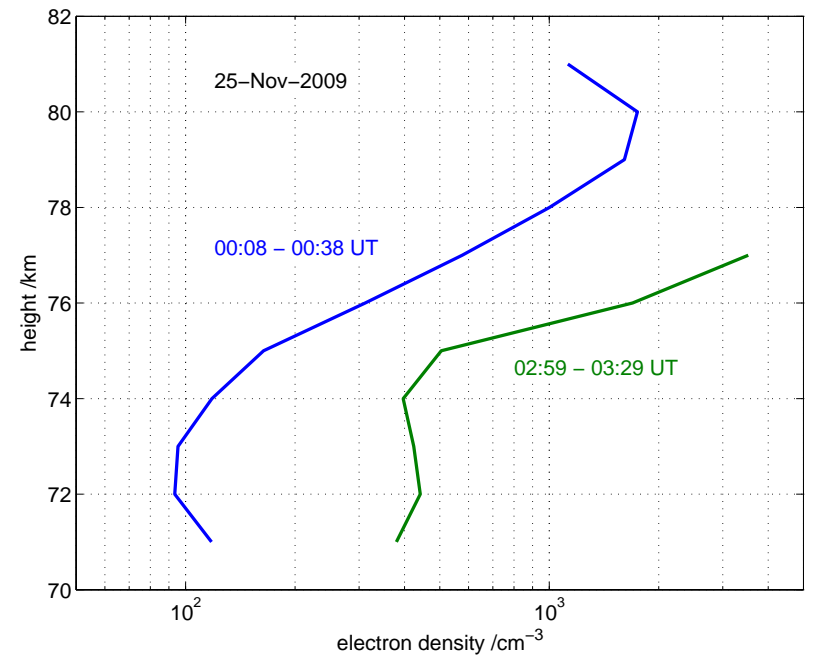

Fig. 8. Median profiles of electron densities derived with the MF radar Saura for 25 November 2009.

exponents between 2.0 and 2.5 (Campistron et al., 2001, and references therein). However, since only relative changes of observed radio noise are considered, the latter frequency dependence cancels out and does not need to be considered further. In addition, we note that Eq. (1) is only valid in the case of weak D-region ionization. This requirement is, however, fully met with cosmic noise absorption values of $0.4 \mathrm{~dB}$ only (see Fig. 9). Using the operating frequencies of $53.5 \mathrm{MHz}$ and $38.2 \mathrm{MHz}$ for the ALWIN-Butler und AIRIS system respectively, absorption ratios between 0.43 and 0.51 are estimated for the frequency dependence mentioned above.

Histograms of the estimated absorption ratios for the compared beams of ALWIN-Butler and AIRIS are depicted in Fig. 10 with 75 bins each histogram. To start with, two out of four histograms reveal mean ratios close to the expected ratio of about 0.5 . The greatest similarity can be seen for the comparison of ALWIN64 Butler beam 16 and AIRIS beam 19, which initially have not been anticipated as those beams are theoretically separated by more than the estimated beam width (Fig. 5). The comparison of this beam combination resulted in a very good correlation factor of 0.97. Furthermore the correlogram (Fig. 9) and absorption ratio of both ALWIN-Butler and AIRIS for the corresponding beams (Fig. 10) underline the similarity. Nevertheless, the other beam combinations in fact still show high correlations of 0.89 to 0.94 . However the cross sections of the considered beams likely still have no perfect overlap and therefore partially differing observation volumes are compared. The histograms for the beam comparisons ALWINButler 16 to AIRIS 19 and ALWIN-Butler 1 to AIRIS 25 show a narrow spread of the absorption ratios and likewise holds for the standard deviation. The mean and median values obtained for both comparisons are close to 0.51 respectively, which is in very good agreement to the theoretically
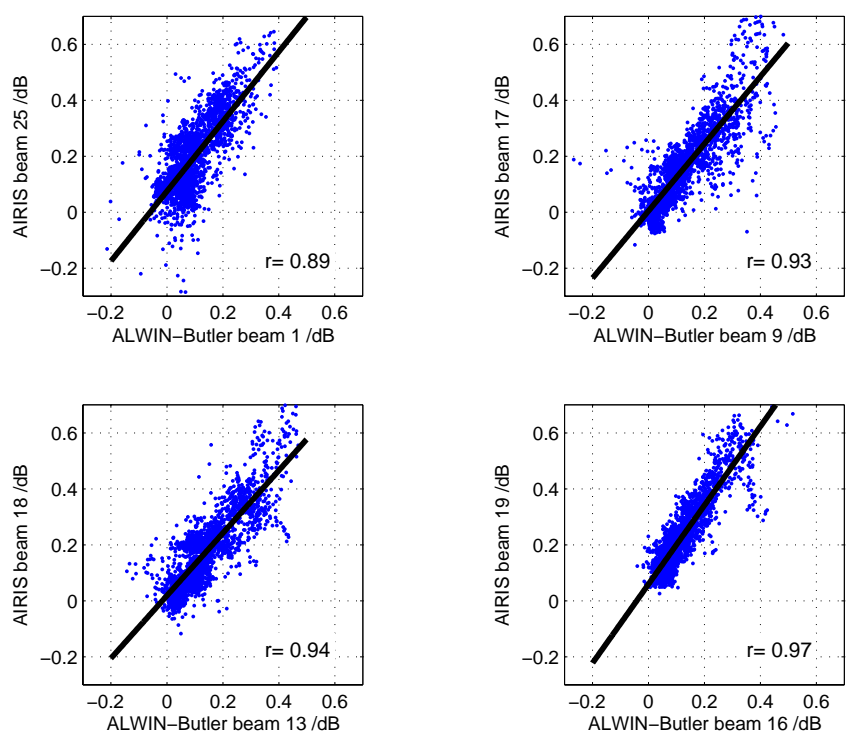

Fig. 9. Correlogram of absorptions estimated for the co-located ALWIN-Butler and AIRIS beams.

expected value of 0.51 (Eq. 1). The comparisons of the remaining beams (ALWIN-Butler 9 to AIRIS 17 and ALWINButler 13 to AIRIS 18) have shown reliable distribution of absorption ratios with a concentration of the mean and median values around 0.75 . However, the correlation factors of at least 0.93 for the compared beams exhibit a very high similarity of the data. This deviation may result from the following potential aspects, (a) lack of perfect overlap of the corresponding beams, (b) different beam pointing zenith angles of the individual beams and therefore different path lengths including a $2-3^{\circ}$ greater beam width for AIRIS results in a significant difference in the size of target areas, (c) imperfect estimation of the QDC, which may be significant as for the main part of the day absorptions of even less than $0.2 \mathrm{~dB}$ have been estimated.

Additionally, from the earlier described experiment, monitoring the noise power received from Cassiopeia A, we concluded a likely offset of beam pointing by about $6^{\circ}$ in azimuth. For the comparison of ALWIN-Butler 9 and AIRIS 17 this $6^{\circ}$ offset in beam pointing leads to an increased spatially displacement of the compared beams as it has been assumed in advance. Furthermore, the slightly greater halfpower beam widths published for the AIRIS beams than the beams simulated for ALWIN-Butler should result in a decrease of the diurnal QDC variation and an increase of the detected absorption as it has been described by Friedrich et al. (2002) and Harrich et al. (2003). An increase of absorption for the AIRIS system due to a broader beam is contrary to the findings in the beam comparisons with absorption ratios of about 0.75 and is therefore not a valid explanation. Especially, as in the earlier comparisons with similar differences in the beam widths have nevertheless resulted in good agreements to the theoretical frequency dependence. Therefore a 

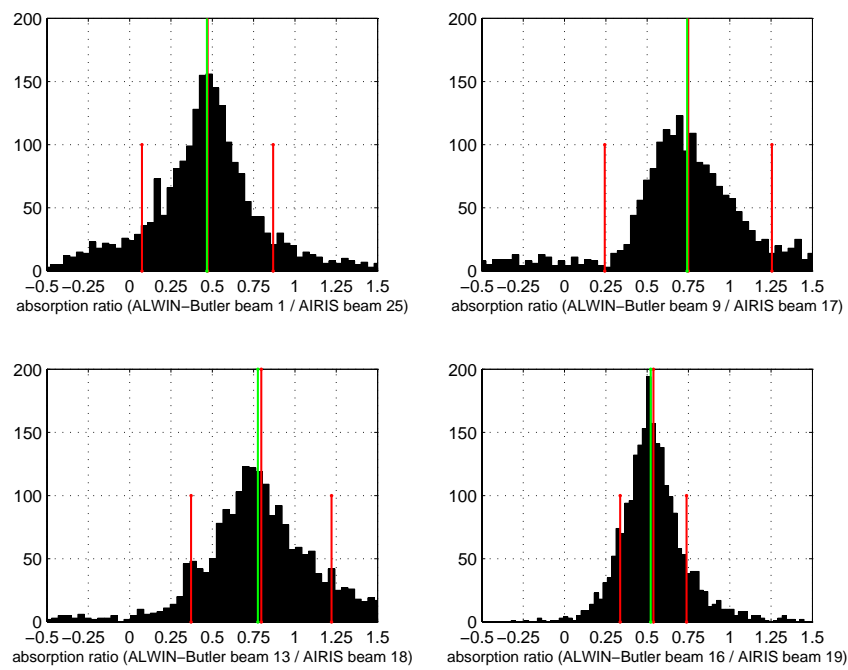

Fig. 10. Histograms of the absorptions ratio between the co-located beams of ALWIN-Butler and AIRIS. Mean and standard deviation are marked with red vertical lines while the median values are marked in green.

flaw in the estimated QDCs and/or likely events of localized effects due to precipitating particles that have been seen with the imperfect matched beam positions and sizes of the two systems may explain the observed deviations. Again, these two beam comparisons have shown very high correlation factors and thus suggesting the existence of co-aligned or at least partially overlapped beams.

\section{Summary and conclusions}

In 2009 the Leibniz-Institute of Atmospheric Physics in Kühlungsborn started to built the new powerful, and more flexible MST radar MAARSY as the successor of the ALWIN radar. With both systems studies of the dynamics and the structure of the polar middle atmosphere have been carried out. The combination of a 16-port Butler matrix with 64 antennas of the former ALWIN array allow observations with simultaneously 16 individual beams. To verify the capability of this beam forming matrix the cosmic radio noise of the supernova remnant Cassiopeia A has been observed. We found a diurnal Quiet Day Curve with reasonable dynamic and a characteristic peak originating from Cassiopeia A. With an overlay of the simulated radiation pattern of one beam with the trajectory of Cassiopeia A we derived the supposedly effective direction observing the radio source. Additionally, from the observations we obtained the associated position of Cassiopeia A. We found a discrepancy between the simulation and the observation, which leads to a likely offset in the beam pointing of about $6^{\circ}$. The multi beam configuration of ALWIN-Butler has also been used in experiments to estimate the cosmic noise absorption at 53.5 MHz. During the period of 18 to 25 November we have observed cosmic noise absorption events with different beams of the ALWIN-Butler configuration and subsequently compared the observations to the co-located imaging riometer AIRIS. To support the observations of ALWIN-Butler and AIRIS, we derived electron density profiles using differential absorption and differential phase measurements from Saura MF radar. We found an increase of electron densities between 70 and $80 \mathrm{~km}$ height at the same times when ALWIN-Butler and AIRIS have estimated an increase of absorption. The simultaneous absorption observations with co-located beams of ALWIN-Butler and AIRIS were highly correlated, up to $97 \%$, leading to the assumption that the beams examined in this study form very similar or at least nearby target areas. Additionally, in two examples we have seen a good agreement to the frequency dependency related to the magneto-ionic theory of AppletonHartree.

Generally, the capability of the beam forming matrix implemented to the MST radar have been verified. Furthermore, we found a good agreement in the observations of ALWINButler and AIRIS implying co-located beam positions and therefore in general beam pointing directions in accordance with the assumed theoretical radiation pattern.

Acknowledgements. The authors would like to thank M. Gausa from the Andøya Rocketrange and the Space Plasma Environment and Radio Science (SPEARS) group, Department of Physics, Lancaster University (UK), permitting access to the data of the AIRIS riometer. Topical Editor Matthias Förster thanks ErnstDieter Schmitter and Ernst Fürst for their help in evaluating this paper.

\section{References}

Andoya Rocket Range: AIRIS riometer, http://alomar.rocketrange. no/iris-and.html, download in January 2011.

Butler, J. and Lowe, R.: Beam Forming Matrix Simplifies Design of Electronically Scanned Antennas, Electronic Design, 9, 170173, 1961.

Campistron, B., Despaux, G., Lothon, M., Klaus, V., Pointin, Y., and Mauprivez, M.: A partial $45 \mathrm{MHz}$ sky temperature map obtained from the observations of five ST radars, Ann. Geophys., 19, 863-871, doi:10.5194/angeo-19-863-2001, 2001.

del Pozo, C. F., Honary, F., Stamatiou, N., and Kosch, M. J.: Study of auroral forms and electron precipitation with the IRIS, DASI and EISCAT systems, Ann. Geophys., 20, 1361-1375, doi:10.5194/angeo-20-1361-2002, 2002.

Friedrich, M., Harrich, M., Torkar, K., and Stauning, P.: Quantitative measurements with wide-beam riometers, J. Atmos. SolarTerr. Phys., 64, 359-365, 2002.

Harrich, M., Friedrich, M., Marple, S. R., and Torkar, K. M.: The background absorption at high latitudes, Adv. Radio Sci., 1, 325327, doi:10.5194/ars-1-325-2003, 2003.

Kero, A., Enell, C.-F., Ulich, Th., Turunen, E., Rietveld, M. T., and Honary, F. H.: Statistical signature of active D-region HF heating in IRIS riometer data from 1994-2004, Ann. Geophys., 25, 407415, doi:10.5194/angeo-25-407-2007, 2007. 
Lancaster University, SPEARS Group: AIRIS riometer, http://www.dcs.lancs.ac.uk/iono/cgi-bin/riometers?orderdir= asc;id=64, download in January 2011.

Latteck, R., Singer, W., and Bardey, H.: The ALWIN MST radar - Technical design and performances, Proceedings of the 14th ESA Symposium on European Rocket and Balloon Programmes and Related Research, 1999.

Latteck, R., Singer, W., Rapp, M., and Renkwitz, T.: MAARSY - the new MST radar on Andøya/Norway, Adv. Radio Sci., 8, 219-224, doi:10.5194/ars-8-219-2010, 2010.
Renkwitz, T., Singer, W., and Latteck, R.: Study of multibeam ability for the VHF MST ALWIN radar system, Proceedings of the 12th International Workshop on technical and Scientific Aspects of MST radars, pp. 127-130, edited by: Swarnalingam, N. and Hocking, W. K., Canadian Association of Physicists, Ottawa, Ontario, Canada, ISBN 978-0-9867285-0-1, 2010.

Singer, W., Latteck, R., and Holdsworth, D.: A new narrow beam Doppler radar at $3 \mathrm{MHz}$ for studies of the high-latitude middle atmosphere, Adv. Space Res., 41, 1488-1494, 2008.

Singer, W., Latteck, R., Friedrich, M., Wakabayashi, M., and Rapp, M.: Seasonal and solar activity variability of D-region electron density at $69^{\circ}$ N, J. Atmos. Solar-Terr. Phys., doi:10.1016/j.jastp. 2010.09.012, 2010. 